\title{
Design of a radiative heat recuperator for steel processes
}

Peru Fernandez Arroiabe ${ }^{1 *}$, Jon Iturralde Iñarga ${ }^{2}$, Mercedes Gómez de Arteche Botas ${ }^{2}$, Susana López Pérez ${ }^{3}$, Eduardo Ubieta Astigarraga ${ }^{3}$, Iñigo Unamuno ${ }^{4}$, Manex Martinez-Agirre ${ }^{1}$, M.Mounir Bou-Ali ${ }^{1}$

${ }^{1}$ Mondragon Unibertsitatea, Faculty of Engineering, Mechanical and Industrial Production, Loramendi 4, Mondragon 20500 Gipuzkoa, Spain.

${ }^{2}$ Tecnalia, Energy and Environment Division, Area Anardi, 5. Azpeitia E20730, Gipuzkoa, Spain.

${ }^{3}$ IK4-Tekniker, Calle Iñaki Goenaga 5, Eibar 20600, Spain.

${ }^{4}$ Sidenor I+ D, Barrio Ugarte S/N, 48970, Basauri, Spain.

\begin{abstract}
In recent years, there has been an increasing interest in the recovery of the waste heat of steel and glass processes. This work proposes a numerical study of a waste heat exchanger system for steel production processes. The radiative energy is transferred to a commercial oil, which can be used to produce electricity. The behavior of the recuperator is analysed using a 3D numerical model, considering the constrains of a real production plant. The influence of the radiation properties of the materials on the temperature and heat transfer rate are also examined. The results show that the absorptivity of the tubes influences significantly the absorbed waste heat. Furthermore, heterogeneous mass flow distribution should be applied to optimize the total heat transfer rate.
\end{abstract}

\section{NOMENCLATURE}

$A:$ Surface area
$c_{\mathrm{p}}:$ Specific heat $\left(\mathrm{J} \mathrm{kg}^{-1} \mathrm{~K}^{-1}\right)$
$F:$ View factor
$\vec{g}:$ Gravity acceleration $\left(\mathrm{m} \mathrm{s}^{-2}\right)$
$h:$ Specific enthalpy $\left(\mathrm{J} \mathrm{kg}^{-1} \mathrm{~K}^{-1}\right)$
$\bar{h}:$ Convection coefficient $\left(\mathrm{W} \mathrm{m}^{-2} \mathrm{~K}^{-1}\right)$
$I:$ Radiation intensity
$k:$ Thermal conductivity $\left(\mathrm{J} \mathrm{s}^{-1} \mathrm{~m}^{-1} \mathrm{~K}^{-1}\right)$
$n:$ Refractive index
$p:$ Pressure $($ Pa)
$t:$ Time $(\mathrm{s})$
$\vec{r}:$ Position vector
$\vec{s}:$ Position vector
$\vec{s}:$ Scattering direction vector
$T:$ Temperature $(\mathrm{K})$
$\vec{v}:$ Velocity vector $\left(\mathrm{m} \mathrm{s}{ }^{-1}\right)$
$\vec{x}, \vec{y}, \vec{z}:$ Direction vectors
$G r e e k$ symbols
$\alpha:$ Absorptivity
$\delta:$ Visibility
$\varepsilon:$ Emissivity
$\kappa:$ Absorption coefficient $\left(\mathrm{m}^{-1}\right.$
$\mu:$ Dynamic viscosity $\left(\mathrm{kg} \mathrm{m}^{-1} \mathrm{~s}^{-1}\right)$
$\rho:$ Density $\left(\mathrm{kg} \mathrm{m}^{-3}\right)$
$\rho$ ': Reflectivity
$\phi:$ Phase function
$\theta:$ Angle between surfaces
$\Omega$ ': Solid angel
$\sigma s:$ Scattering coefficient
$\sigma$. Stefan-Boltzmann constant $\left(5.669 \times 10^{-8} \mathrm{Wm}^{-2} \mathrm{~K}^{-4}\right)$
Subscripts
in: Inlet

Abbreviations

S2S: Surface to surface

CFD: Computational fluid dynamics

\section{INTRODUCTION}

As a result of the changes of environmental policies, such as H2020 in Europe, there has been an increasing interest in waste heat recovery in recent years. According to Kesicki et al. [1], the industry sector needs a third part of the total energy consumption of the world. Furthermore, it is one of the most interesting sector to recover the waste heat because of its high Carnot potential [2]. Particularly, the waste heat of iron and steel making processes present a great opportunity for energy use. On the one hand, it is the largest energy consuming industrial process [3]; it can be reach $4-5 \%$ of the total world energy consumption [4]. On the other hand, the exhaust gas temperature can reach $1450-1500^{\circ} \mathrm{C}[5]$.

A considerable amount of literature has been published on the waste heat recovery in iron and steel industries. Villar et al. [6] examined the state of art of waste heat recovery technologies of 5 representative sectors in continuous industrial processes. They presented a case study made in the steel sector, achieving emissions reductions greater than 85 . Most of the subsequence studies have been focused on the recovery of molten slags. Zhang et al. [4] made a review of technologies to recover waste heat of molten slags in the steel industry. They focused on dry granulation methods, suggesting some technical difficulties to be considered. In the same vein, Liu et al. [7] developed a gravity bed waste heat boiler to recover the heat of high-temperature slag particles. They analysed the influence of different design parameters on the efficiency of the boiler, such as Reynolds number and particle dimensions, getting efficiencies greater than $90 \%$. Gutiérrez et al. [8] designed an innovative prototype to capture the waste heat of steel slags, principally by

\footnotetext{
* Corresponding author: parroiabe@mondragon.edu
} 
conduction, using molten salts to recover it. Originally, they studied the influence of design parameters on the performance of the recuperator using CFD numerical models. Their results showed an efficiency around 92\% and they suggested the optimum length for the recuperator to employ in a Rankine cycle. Furthermore, [3] designed a flat heat pipe heat exchanger to recover the heat by radiation and convection from steel industry. They carried out experimental tests showing that the proposed technology could be a promising technology to recover the waste heat in applications with hot source temperatures higher than $450^{\circ} \mathrm{C}$.

This work shows a 3D numerical study to analyse the behaviour of the recuperator for steel processes. After ensuring the mesh independency, the influence of the absorptivity of the tubes is studied. Furthermore, the total heat transfer and the oil temperature jump inside the tubes for the proposed design are analysed.

\section{ANALYSIS AND MODELING}

\subsection{Computational domain, boundary conditions and mesh}

Fig. 1 shows the scheme of the recuperator, Fig. 2 the isometric view of the domain, and Fig. 3 the mesh of the model. The model was built considering the constrains and dimensions of a real steel making plant, namely SIDENOR. The model considered the minimum safety length from the steel bloom in both horizontal and vertical directions. In order to reduce the number of elements, one meter ( $\mathrm{z}$ direction) of the whole recuperator was modeled. Moreover, symmetry boundary condition was considered in the centre plane of the $x$ direction.

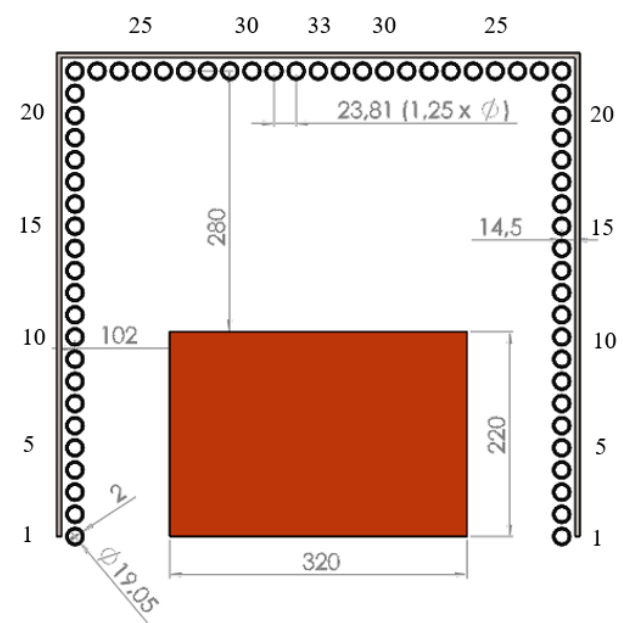

Fig. 1: Scheme of the recuperator

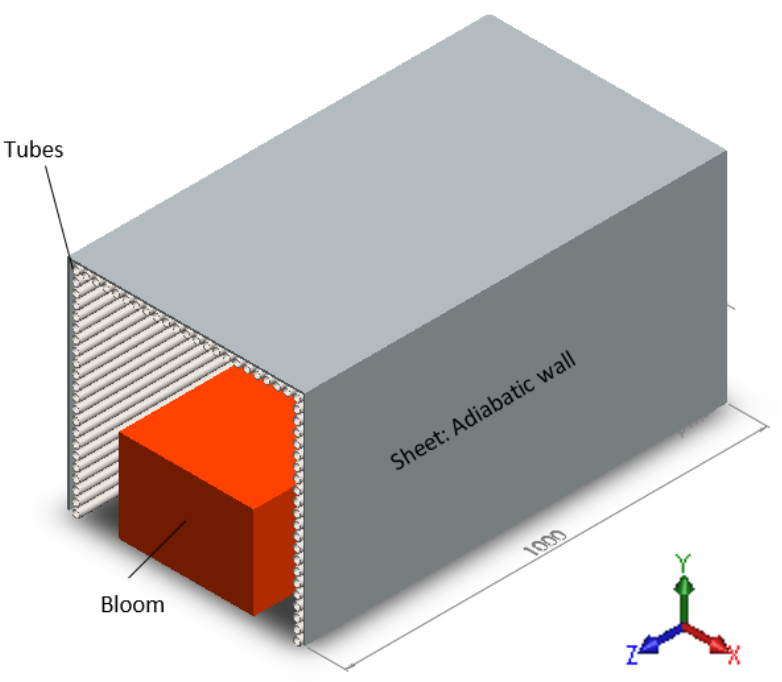

Fig. 2: Isometric view of the recuperator

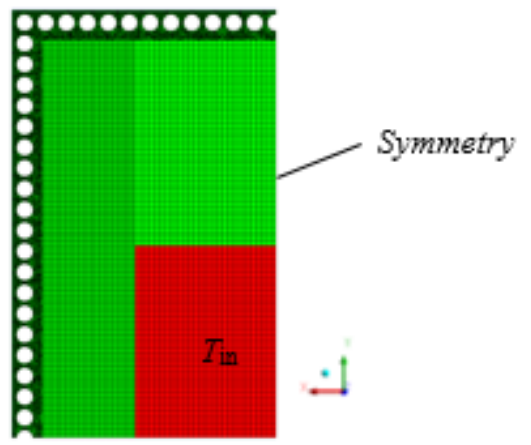

Fig. 3: Mesh of the model

The domain consisted of a hot steel bloom, surrounded by 65 tubes and the cover, all of them made by stainless steel, which gave the shape of a tunnel. The bloom had a transversal area of $320 \times 220 \mathrm{~mm}^{2}$ and it entered into the domain (z-) at $T_{\text {in }}=1000{ }^{\circ} \mathrm{C}$ and $v_{\text {bloom }} 1.2 \mathrm{~m} / \mathrm{min}$. The bottom ( $\left.\mathrm{z}^{-}\right)$and backside $\left(\mathrm{z}^{+}\right)$faces of the bloom were considered as adiabatic faces. The emissivity of the faces of the bloom was considered as cbloom $=0.82$.

The heat transferred by radiation is captured by the oil that flows through the interior of the tubes. The external diameter and thickness of the tubes were $19.05 \mathrm{~mm}$ and 2 $\mathrm{mm}$, respectively and the intertube spacing was $23.81 \mathrm{~mm}$ (1.25 times the external diameter). In this study, the effect of the absorptivity of the tubes was studied. When the surface is considered grey and opaque, absorptivity is equal to emissivity [9]. Thus, two different emissivities of the surface of the tubes were analysed, which were the original emissivity, $\varepsilon_{\text {tube }}=0.8$, and the emissivity of the surface treatment $\left(\varepsilon_{\text {tube }}=0.97\right)$. The interior faces of the tubes were set as the Newton boundary condition. The selected oil was Syltherm 800, from Dow chemical company. The convection coefficient was calculated using Dittus-Boelter equation [10], which was $\bar{h}_{\text {oil }}=1317 \mathrm{Wm}^{-2} \mathrm{~K}^{-1}$. The temperature of the oil was considered $T_{\mathrm{oil}}=360^{\circ} \mathrm{C}$. 
In contrast, the objective of the cover was to reflect the amount of the radiation heat lost through the gaps between the tubes. The material of the sheet was stainless steel and it had a thickness of $5 \mathrm{~mm}$. In the model, it was considered as an adiabatic wall, with $\varepsilon=0.8$.

The most of the domain was meshed with structured elements. Just in the zone close to the tubes unstructured mesh was employed (Fig. 3). In addition, in this zone the grid was refined to properly capture de natural convection. As a result of the symmetry condition, the mesh only considered the half of the whole tubes, that is to say, 33 tubes.

Table 1. Material properties and working conditions

\begin{tabular}{lc}
\hline Bloom inlet temperature, $\mathrm{T}_{\text {in }}\left({ }^{\circ} \mathrm{C}\right)$ & 1000 \\
Bloom surface emissivity, $\varepsilon_{\text {bloom }}$ & 0.82 \\
Bloom thermal conductivity, $k_{\text {bloom }}$ & 27 \\
$\left(\mathrm{~W} \mathrm{~m} \mathrm{~m}^{-1} \mathrm{~K}^{-1}\right)$ & 1.6 \\
Vbloom, $(\mathrm{m} / \mathrm{min})$ & $0.8-0.97$ \\
Tube surface emissivity, $\varepsilon_{\text {tube }}$ & 27 \\
Tube thermal conductivity, $k_{\text {tube }}$ & $360^{\circ} \mathrm{C}$ \\
Syltherm oil temperature, $T_{\text {oil }}\left({ }^{\circ} \mathrm{C}\right)$ & 1317 \\
Syltherm oil convection coefficient, $h_{\text {oil }}$ & \\
$\left(\mathrm{W} \cdot \mathrm{m}^{2} \mathrm{~K}^{-1}\right)$ & 0.8 \\
Sheet surface emissivity $\varepsilon_{\text {sheet }}$ & 27 \\
Sheet thermal conductivity $k_{\text {sheet }}$ & \\
\hline
\end{tabular}

The faces between the bloom and the tubes in both inlet, outlet and bottom parts, were set as pressure inlet boundary conditions with $\varepsilon=1$ and $T=27^{\circ} \mathrm{C}$.

\subsection{Governing equations}

The software Ansys Fluent 19.0 was used to solve the governing equations. This software is based on the finite volume method. The solved continuity, momentum and energy equations were:

$$
\begin{aligned}
& \frac{\partial \rho}{\partial t}+\nabla(\rho \vec{v})=0 \\
& \frac{\partial}{\partial t}(\rho \vec{v})+\nabla(\rho \vec{v} \vec{v})=-\nabla p+\nabla(\mu \nabla \vec{v})+\rho \vec{g} \\
& \frac{\partial}{\partial t}\left(\rho c_{p} T\right)+\nabla\left(\rho \vec{v} c_{p} T\right)=\nabla(k \nabla T)
\end{aligned}
$$

The radiative heat transfer plays a great role on the heat captured by the recuperator. The radiative heat transfer equation for an absorbing, emitting and scattering medium at position $\vec{r}$ and in the direction $\vec{s}$ is [11]:

$$
\frac{d I(\vec{r}, \vec{s})}{d s}+\left(\kappa+\sigma_{s}\right) I(\vec{r}, \vec{s})=a n^{2} \frac{\sigma T^{4}}{\pi}+\frac{\sigma_{s}}{4 \pi} \int_{0}^{4 \pi} I\left(\vec{r}, \vec{s}^{\prime}\right) \phi\left(\vec{s}, \vec{s}^{\prime}\right) d \Omega
$$

Particularly, the S2S model was used to account the radiation exchange. This model assumes that any radiation is not absorbed by the fluid and that the surface is gray and diffuse. Moreover, according to Kirchoff's law, the absorptivity is equal to emissivity $(\alpha=\varepsilon)$ [9]. As in the case the present study all the solids can be considered opaque, the transmissivity can be neglected, giving: $\alpha=1-\rho^{\prime}$. Thus, the amount of energy upon a surface from another surface only depends on their size, separation distance and orientation, called the view factor. The view factor is the fraction of energy leaving the surface that is incident in the other surface, and between two finite surfaces $i$ and $j$ is given by:

$$
F i j=\frac{1}{A_{i}} \int_{A_{i}} \int_{A_{j}} \frac{\cos \theta_{i} \cos \theta_{j}}{\pi r^{2}} \delta_{i j} d A_{i} d A_{j}
$$

\section{RESULTS AND DISCUSSION}

First, to check the influence of the mesh, the independence of the mesh is presented. Once, the mesh independency is verified, the influence of the absorptivity of the tubes on the heat transfer rate is evaluated. Finally, the results of the local heat transfer rate of the tubes and the temperature jump of each tube are analysed.

\subsection{Mesh independence}

To ensure the mesh independency, the total heat transfer rate of the tubes were studied for 8 different grids. Fig. 4 Erreur ! Source du renvoi introuvable. shows the total heat transfer rate (grey colour) and the difference (black colour) for the different grids. The error was calculated respect to the case $5 \mathrm{~mm}-1 \mathrm{~mm}$. $5 \mathrm{~mm}-1 \mathrm{~mm}$ means that the maximum element size near the tubes is $1 \mathrm{~mm}$, whereas in the rest of the domain is $5 \mathrm{~mm}$. The selected grid was $10 \mathrm{~mm}-1 \mathrm{~mm}$.

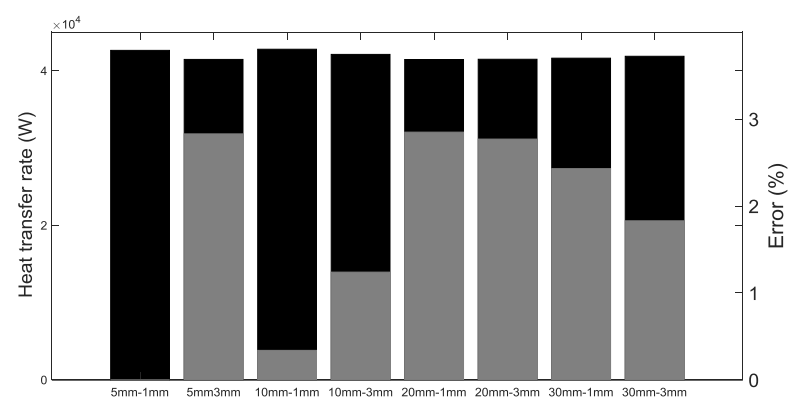

Fig. 4: Total heat transfer rate (grey) and the error between different grids (red)

\subsection{Influence of the absorptivity of the tubes}

In the literature there are different surface treatments to increase the absorptivity of stainless steel tubes at high temperatures [12]. However, this would also increase the cost of the products and it is essential to evaluate its influence. Fig. 5 shows the total heat transfer and 
radiation heat transfer rate for untreated (grey) and treated (black) tubes. The results reveal there is an increase of almost $9 \%$ in the total heat transfer rate when the tubes are treated, as a result of the growth in the radiation exchange. In contrast, the convection mechanism cools the tubes. Therefore, the tubes should be treated to increase the efficiency of the recuperator and the results shown the following sections have been obtained with treated tubes.

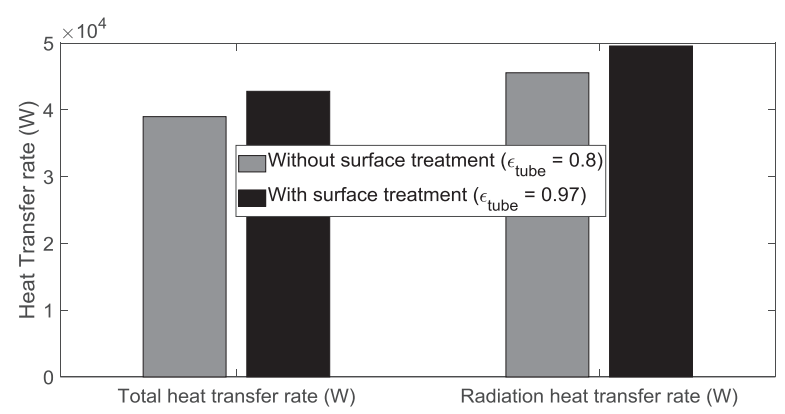

Fig. 5: Total and radiation heat transfer rate for tubes without (grey) and with (black) surface treatment

\subsection{Local heat transfer rate}

The study of the heterogeneities in the local heat transfer of the tubes as a result of differences on the view factor is essential for designing a safety recuperator. This dissimilitude grows the risk of achieving temperatures higher than the maximum recommended temperature, that is $T=400^{\circ} \mathrm{C}$. Fig. 6 shows the local heat flux transferred from the bloom to the oil of the half model.

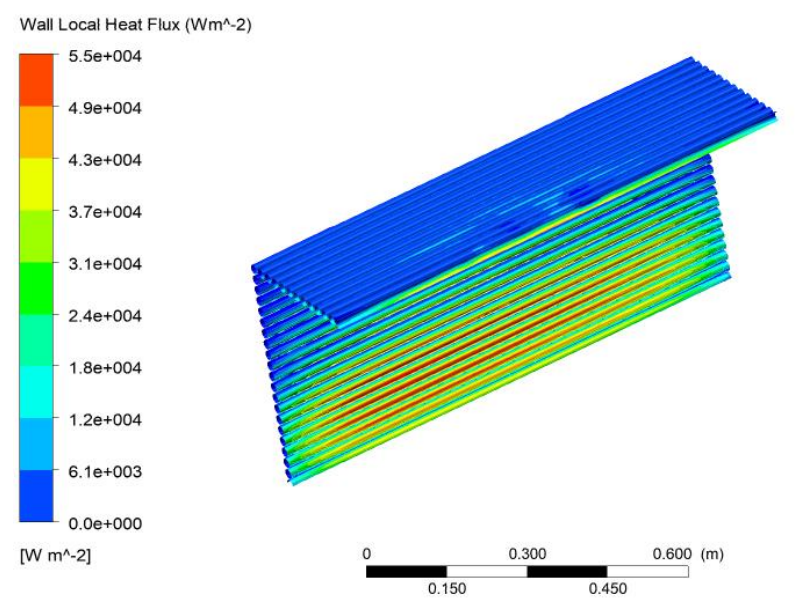

Fig. 6: Local wall heat flux of the tubes.

There are great differences in the total local wall heat flux between tubes. Because of the direct irradiation from the bloom, the heat transfer rate is much higher at the bottom part of the tubes. Furthermore, there is a difference of an order of magnitude between zones in this part. The maximum values are located in the centre of the tubes 48 and 28-31. These dissimilarities could rise mechanical tensions along the tubes.

\subsection{Total temperature jump of tubes}

Considering the amount of the total heat transferred to each tube and the mass flow rate and properties of the oil Syltherm 800 , the temperature jump of the fluid per onemeter length can be calculated for each tube. Fig. 7 shows the temperature jump for the tubes 2-32. The maximum temperature rise takes place in the tube number 6 , almost $3^{\circ} \mathrm{C}$, whereas the minimum jump is in the tube number 21 . Interestingly, this tube is located near the corner and the temperature jump is proximate to $1^{\circ} \mathrm{C}$. As $T=400^{\circ} \mathrm{C}$ is the constraining factor, it has to be ensured that the temperature of the oil never reaches this value. With a homogeneous mass flow rate, the outlet temperature in the other tubes would be far of this value. Therefore, the nonhomogeneous distribution of the mass flow rate should be considered for future designs.

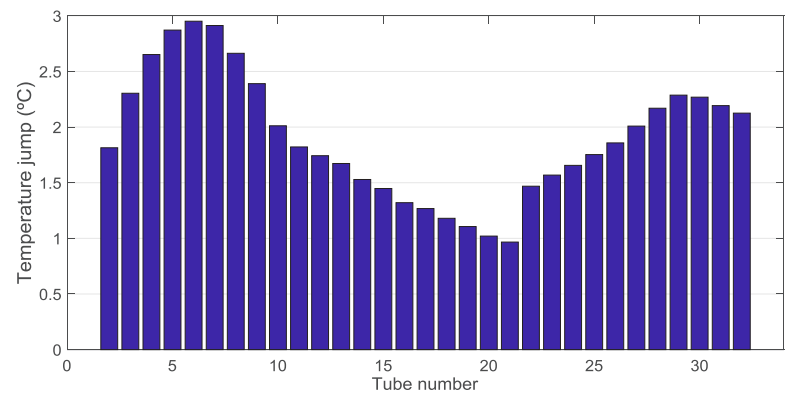

Fig. 7: Temperature jump of the oil in each tube

\section{CONCLUSIONS}

In this work the behaviour of a waste heat recuperator for steel making processes under real conditions was analysed. The results showed the absorptivity of the surface of the tubes had a great influence on the recovered heat and it should be applied. In addition, there were great differences on the local heat transfer rate between different parts of the recuperator. This differences lead to dissimilarities in the temperature jump of each tube. These should be considered to design secure and efficient recuperators, that is, for not exceeding the maximum temperature in any zone and for achieve the same temperature in the outlet of the tubes. Otherwise, the maximum temperature of the fluids could achieve, or the efficiency could decrease considerably. For all these reasons, mass flow rate heterogeneous distribution between tubes should be considered to optimize the design of this kind of recuperators.

The authors would like to express their gratitude for the support of: BEROA-GO 3.0 (KK-2018/00022), BEROA-GO 4.0 and Research Groups (IT1009-16) of Basque Government and FETRAFLU (2018-CIEN-000101-01) from Gipuzkoa Program.

\section{References}

1. Kesicki F., Yanagisawa A., IEA's World Energy Outlook Energy Effic. 8, 155 (2014). 
2. Forman C., Muritala I.K., Pardemann R., Meyer B. Renew. Sustain. Energy Rev., 57, 1568 (2016).

3. Jouhara H, Almahmoud S, Chauhan A, Delpech B, Nannou T, Tassou S A, Llera R, Lago F, Arribas J J Energy Procedia, 123, 329 (2017).

4. Zhang H, Wang H, Zhu X, Qiu Y J, Li K, Chen R, Liao Q, Appl. Energy, 112, 956 (2013).

5. Department of Energy, US Manufacturing and Minin, (2004).

6. Villar A, Arribas J J, Parrondo J, Clean Technol. Environ. Policy, 14, 29 (2012).

7. Liu J, Yu Q, Peng J, Hu X, Duan W, Int. Commun. Heat Mass Transf., 69, 23 (2015).

8. Gutiérrez Trashorras A J, Álvarez E Á, Río González J L, Suarez Cuesta J M, Bernat J X, Appl. Therm. Eng., 56, 11 (2013).

9. Modest M F, Radiative Heat transfer (McGraw-Hill) (1993).

10. Dittus F, Boelter L M . Publications on Engineering 2 (University of California on Engineering 2) (1930).

11. ANSYS FLUENT theory guide ANSYS, Inc., Canonsburg, PA (2011).

12. Ho C K, Mahoney A R, Ambrosini A, Bencomo M, Hall A, Lambert T N, ASME, Proceedings of the ASME 2012 6th International Conference on Energy Sustainability, ES 2012 (San Diego, CA, USA). 